\title{
HOW DO CHILDREN RESPOND TO DIFFERENT ARTISTIC GENRES?
}

Lilly K. V.,

Sudhakar Venukapalli ${ }^{i}$

Department of Education, The English and Foreign Languages University, Hyderabad, India

\begin{abstract}
:
Art is as beautiful as sunshine and as important as nourishment to our body. Though art is a stimulating aspect, art appreciation is regarded as a highly subjective phenomenon. Art education and art appreciation is known to enrich the lives of children. Various factors including one's experience, knowledge, and exposure to arts as well as processing fluency are known to influence one's aesthetic appreciation. The objective of the present study is to examine children's expressions of art appreciation. The quantitative study examines how children respond to artworks from different artistic genres. The participants in this study are sixty grade IX children in the age group of 13-15 years, from rural and urban backgrounds from the state of Telangana. The study employed equal number of boys and girls. Images of nine famous artworks depicting landscapes are used as stimuli. The images of artworks belonged to three artistic genres: representational, semi-representational, and abstract artworks. The artworks are selected from Western, Middle Eastern and Oriental paintings. Images of paintings are shown randomly to children to elicit their responses. The results of analysis of children's descriptions of paintings indicate that children appreciated representational artworks more than semi-representational artworks and their appreciation of abstract artworks is minimum. Children's appreciation of artworks according to the type of paintings indicate differences in appreciation among western, middle eastern and oriental paintings. The statistical analysis of overall appreciation of three genres of artworks depending on the type of paintings reveal that there exists a statistically significant difference in the appreciation of three types of artworks depending on the genre of artworks. The findings of this study can be used to enlighten the development of art education curricula.
\end{abstract}

Keywords: art appreciation, art education, aesthetic experience, artistic genres, abstract art and representational art

i Correspondence: email sudhakarvenu.efluniversity@gmail.com 


\section{Introduction}

Art is as beautiful as sunshine and as important as nourishment to our body. Many researchers tried to find out why art exists. The same visual displays provide different aesthetic experiences to viewers from different cultural and social backgrounds (Palmer et al., 2013). "Aesthetic processing is understood as being embedded in cultural contexts and modulated by social conditions" (Bao et al., 2016). Though art is regarded as one of the most fascinating aspects of human life (Schabmann et al., 2015), aesthetic appreciation is highly subjective. Art cannot be separated from culture because art itself is culture. It is important that "students be allowed to comprehend art in a cultural context and experience and acknowledge the influence of culture through arts" (Jiao, 2019).

\section{Art appreciation in children}

Since independence, India focused on the overall development of students and it is evident through various policy documents. The importance of arts, arts education, and aesthetic experience in shaping the life of a child is mentioned in all policy documents. Previous researchers on art and aesthetic experience have identified various factors that influence art appreciation. With the advancement of science and technology, neuroscientists have also ventured into the field of psychology of aesthetics and identified neural processes associated with art appreciation. Art education generates creativity, communication and intelligence and hence considered particularly important in life (Maneen, 2016; Savva \& Trimis, 2005; Terreni, 2016). Art appreciation as part of art education can "widen the vision of students" (Law, 2010). It also helps children develop communication skills (Novaković, 2015) and generate selfconfidence (Ariffin, 2010 cited in Ping \& Ladin, 2019). In schools, though children are engaged in some art making, their opportunities to view art are limited. Studies suggested that "if adults can meaningfully engage children in conversation about artworks, they will be equipped with the ability to reflect on their own artworks as well as adult artworks" (Anderson et al., 2002). Why there should be discussion on art objects in classrooms? Efland (2002) argued that arts are cognitively significant because "they provide encounters that foster the capacity to construct interpretations." (p.161).

In modern terms, the processing fluency theory provides the most powerful explanation of aesthetic appreciation. (Palmer, Schloss, \& Sammartino, 2013). The fluency theory suggests that the mechanism of mental ease explains how aesthetic pleasure is obtained from art (Reber, Schwarz \& Winkielman, 2004; Reber et al., 1998; Winkielman et al., 2006). Several psychological studies have found that people's experience and knowledge of art results in significant differences in aesthetic appreciation (Barron \& Welsh, 1952; Munsinger \& Kessen, 1964; Winston \& Cupchik, 1992).

Why human mind appreciates challenging art? Research suggests that "art provides the possibility to gain new information and expand the acquired knowledge and offers opportunities for mental growth" (Armstrong \& Detweiler-Bedell, 2008). Experimental aesthetics investigates the importance of art in human society and its presence in all cultures. Recent art appreciation theories (Chatterjee, 2003; Leder et al., 2004) suggest that there exists an interaction between the cognitive and emotional factors influencing aesthetic appreciation. Art appreciation includes 
varied activities including the ways of responding to an artwork, interpreting an artwork, and understanding the artwork that aims at its meaning. Law (2010) argues that all students should be exposed to issues and debates related to art in order to cultivate an intellectual response to art. Kieran (2012 cited in Sherman \& Morrissey, 2017) argued that "art appreciation is an intrinsically valuable skill that allows one to cultivate excellences of character, because practiced arts engagement allows one to better imagine and critically examine not only aesthetic qualities of artworks, but also artistic originality, emotional expression, insight and moral understanding." (p. 23). Research suggests that aesthetic appreciation of artworks foster "holistic thinking and reasoning" (Eglinton, 2003) which enriches visual literacy (McArdle \& Wright, 2014; Rudolf \& Wright, 2015).

Children express their wonder and amazement during a visual encounter and their aesthetic responses are clearly shown through their spontaneity. While viewing artworks, children understand varied interpretations of familiar themes. Through this process children learn to appreciate artworks and comprehend that "each artwork is a unique expression of the artist" (Eckhoff, 2010). Children can also make connections between what is depicted in the artwork and their own personal experiences (Kolbe, 2002; Mulcahey, 2009; Savva, 2003). The artworks can act as a suitable visual medium for the children to verbally express their thinking (Housen, 2002; Perkins, 2003). Children used their perceptual abilities and conceptual knowledge to respond to the artworks. Research indicates that art is a principal medium of human communication. House \& Rule (2005) suggests that "when children interpret artworks, they develop inventive problem-solving abilities, apply analytic and synthetic forms of reasoning, and learn to exercise judgement."

Research conducted by Kate Rawlinson's team at The Wolfsonian-Florida International University, an art and design museum in Miami Beach using the Artful Citizenship curriculum integrating arts in the curriculum using Visual Thinking Strategies (VTS) showed that integrating art in the curriculum is not just art for art's sake but provides "distinct contribution to students" critical thinking skills and measurable academic achievement as well" (Burchenal et al., 2008). Viewing and experiencing art may help children become self-directed learners to enrich the creative and innovative thinking processes that are valued as 21 $1^{\text {st }}$ century skills (Bellanca \& Brandt, 2010). Therefore, it is imperative to know how children perceive and respond to works of art. More knowledge about children's art appreciation may help teachers and teacher educators in designing curriculum and providing right kind of learning experiences in classrooms.

\section{The objectives}

The objective of the present study is to examine children's expressions of art appreciation. The quantitative study examines how children respond to artworks from different artistic genres. Children's expressions of art appreciation are elicited through their descriptions of artworks.

\section{The methodological procedures}

The participants in this study are sixty grade IX children in the age group of 13-15 years, from rural and urban backgrounds from the state of Telangana. The study employed equal number of boys and girls. 
Table 1: Description of sample

\begin{tabular}{|l|c|c|c|c|}
\hline Age of children (years) & Mean & Standard deviation & Age range (years) & N \\
\hline Rural & 14.7 & 0.58 & $13-15$ & 30 \\
\hline Urban & 13.6 & 0.56 & $13-15$ & 30 \\
\hline Girls & 14 & 0.91 & $13-15$ & 30 \\
\hline Boys & 14.3 & 0.75 & $13-15$ & 30 \\
\hline Total & 14.2 & 0.81 & $13-15$ & 60 \\
\hline
\end{tabular}

To avoid the mediated effect of art-related knowledge (Leder et al., 2006), the researcher examined only art naïve participants without prior systematic art-related education and art training. The sample selected had no formal art education as reported in the Art Expertise Questionnaire. The Art Expertise Questionnaire collected information on the participants' interest in arts, any art education classes attended, and the time spent on arts activities on a weekly basis. The children are initially informed about art appreciation, paintings by various artists, paintings belonging to different artistic genres and the procedures involved in the study.

To measure children's expressions of art appreciation, images of nine famous artworks depicting landscapes are shown. Children prefer landscapes as well as those with water or distance. (Gardner et al., 1975). Landscapes depict a scenic view which includes hills, mountains, river, forests etc. The images of artworks shown to children belonged to three artistic genres:

1) representational,

2) semi-representational, and

3) abstract artworks.

The artworks are selected from Western, Middle Eastern and Oriental paintings. The paintings are chosen based on relevant books on art history and intersubjective agreement of art experts. Until mid-19 ${ }^{\text {th }}$ century, western paintings were primarily concerned with representational and classical modes of production. Presently western style includes modernism, cubism, surrealism, expressionism, abstract style, and impressionism. The artworks characterise specific artistic periods: Renaissance/Baroque, Impressionism and Abstraction. Middle eastern (West Asia) paintings are dominated by Muslim decorative arts and includes stylized geometric and floral motifs. Oriental paintings or Asian art originated from various Asian cultures and reflect on the society in which it was produced. Oriental art includes Chinese, Japanese, Korean and Indian art along with art from Central and Southeast Asia. Three different types of paintings are included in the study as they portray stylistic characteristics and culture of that region.

The Representational artworks attempt to recreate the landscape in a realistic way. In a semirepresentational artwork, the landscape appears realistic from far but when comes close, the brushstrokes seem to be slightly distorted. In abstract artworks, colour, line, and form are distorted and there is no similarity to an actual landscape. No explicit content is evident in abstract art and importance is given to style. According to Brinkmann, Commare, Leder, \& Rosenberg (2014), "abstract art represents a universal class of images that could be understood by everyone because they lack semantic content."

Children prefer landscapes as well as those with water or distance. Artistic characteristics such as colours, medium used and design quality also influence children's preferences. Artistic style of the painting such as abstract, realistic, older, or modern also influences the art 
appreciation of children. "The selection of art styles from representative to abstract can help to understand the developmental progression in art appreciation of children" (Gardner et al., 1975).

Images of paintings are shown to children using a projector. All the nine artworks belonging to three artistic genres, i.e., representational, semi-representational and abstract artworks selected from Western, Middle Eastern and Oriental collections are shown randomly to children to elicit their responses. Images of artworks are presented in uncompressed jpg file colour format and the dimensions of various images differed. All images were reduced in size to 1024 pixels. Prior to presenting the target image few sample images of artworks are shown to children to help children comprehend the procedure. All images are shown approximately for five to ten minutes to ensure the completion of children's descriptions of the artworks.

To ensure reliability of the study, all test procedures are administered in a similar pattern for all participants in order to obtain precise and stable results. The conditions of the tests are standardised, the circumstances are made consistent to reduce any external factors. Sample are selected from the same grade, age group and geographic location in order to produce valid results of the study.

Children's expressions of artworks are coded on a continuous scale of 1-10 for all three genres of artworks for computing their appreciation. Their overall descriptions of artworks on a continuous scale of 1-10 are tabulated for representational, semi-representational and abstract artworks. The data obtained is tested for normality using Shapiro-Wilk test and assumed to be non-normal. Therefore, non-parametric statistical tests are conducted for analysing the data. Statistical tables are generated for children's expressions of art appreciation by genre (representational, semi-representational and abstract). To test the differences between children's appreciation of representational, semi-representational and abstract artworks, Friedman test is used. Post-hoc tests are conducted using Wilcoxon signed ranks test by applying Bonferroni adjustment on different combinations of the three genres of artworks to investigate where the differences occur. To find out children's appreciation of artworks with respect to type of paintings namely, Western, Middle eastern and Oriental paintings, Friedman test is used followed by post-hoc test using Wilcoxon signed ranks test.

\section{Findings of the study}

\subsection{Children's appreciation of artworks with respect to genre}

Children's descriptions of artworks are scored on a continuous scale of 1-10 for all three genres of artworks namely, representational, semi-representational and abstract artworks. Results of the analysis of overall appreciation of artworks are shown below.

The scores of children are categorised into low, medium, and high according to the scores obtained by children. A score of 1 to 3 is considered as a low score, score of 4 to 7 as medium score and a score of 8 to 10 is regarded as a high score. The results are presented in the following chart.

The results represented in the chart reveals that majority of children obtained a medium score of 4 to 7 for representational and semi-representational artworks. For representational artworks, 52 children (86.6\%) scored medium score and for semi-representational artworks, 59 children (98.3\%) scored the medium score. Abstract artworks showed a different pattern where 
35 children $(58.3 \%)$ had a low score and 25 children $(41.6 \%)$ are in the medium score category. None of the children has a high score for abstract artworks.

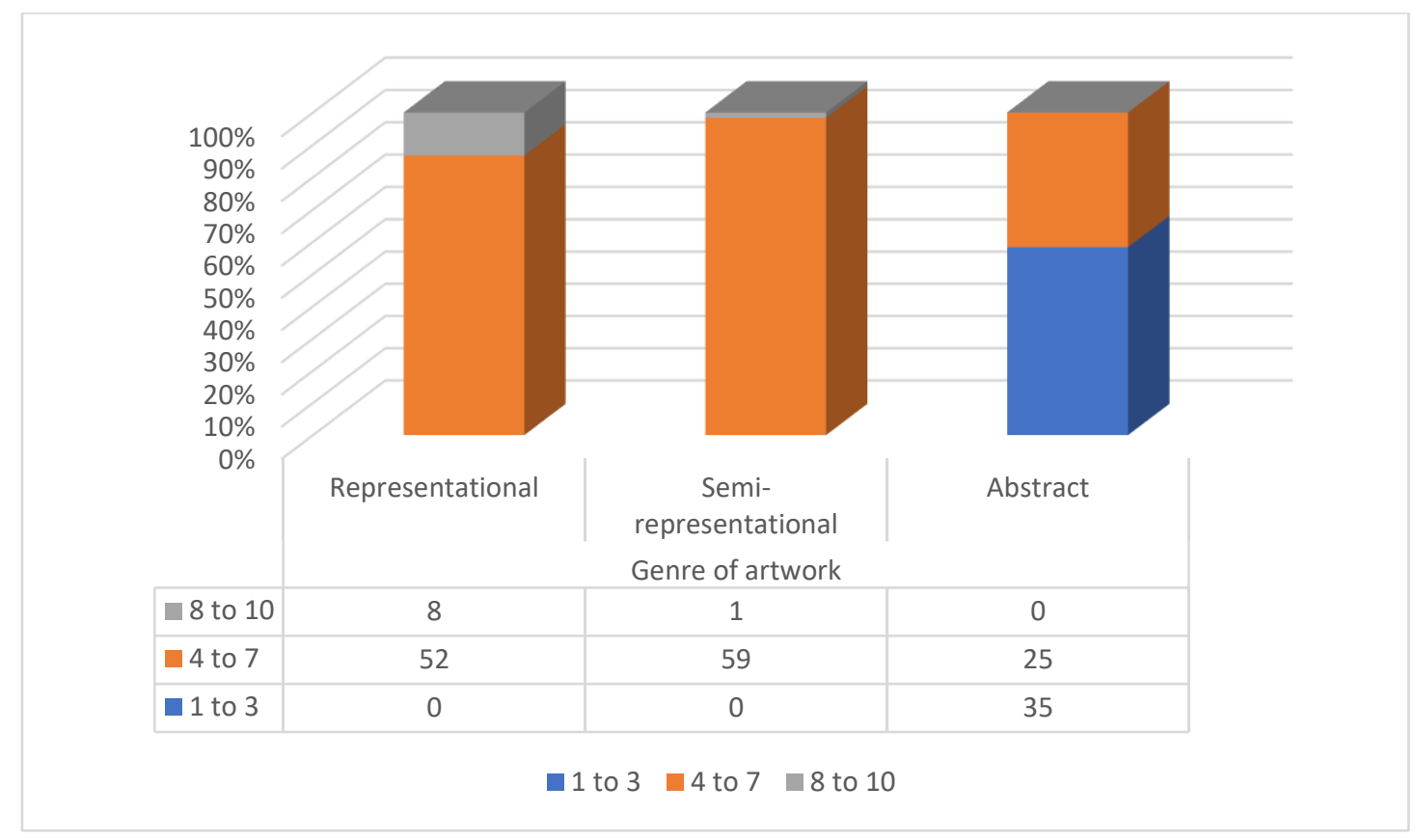

Figure 1: Distribution of scores of children

The scores obtained by children on a continuous scale of 1-10 are totalled for all three genres of artworks. This figure will give us an insight into the overall art appreciation pattern of children. The total scores of children for representational, semi-representational and abstract artworks are given below:

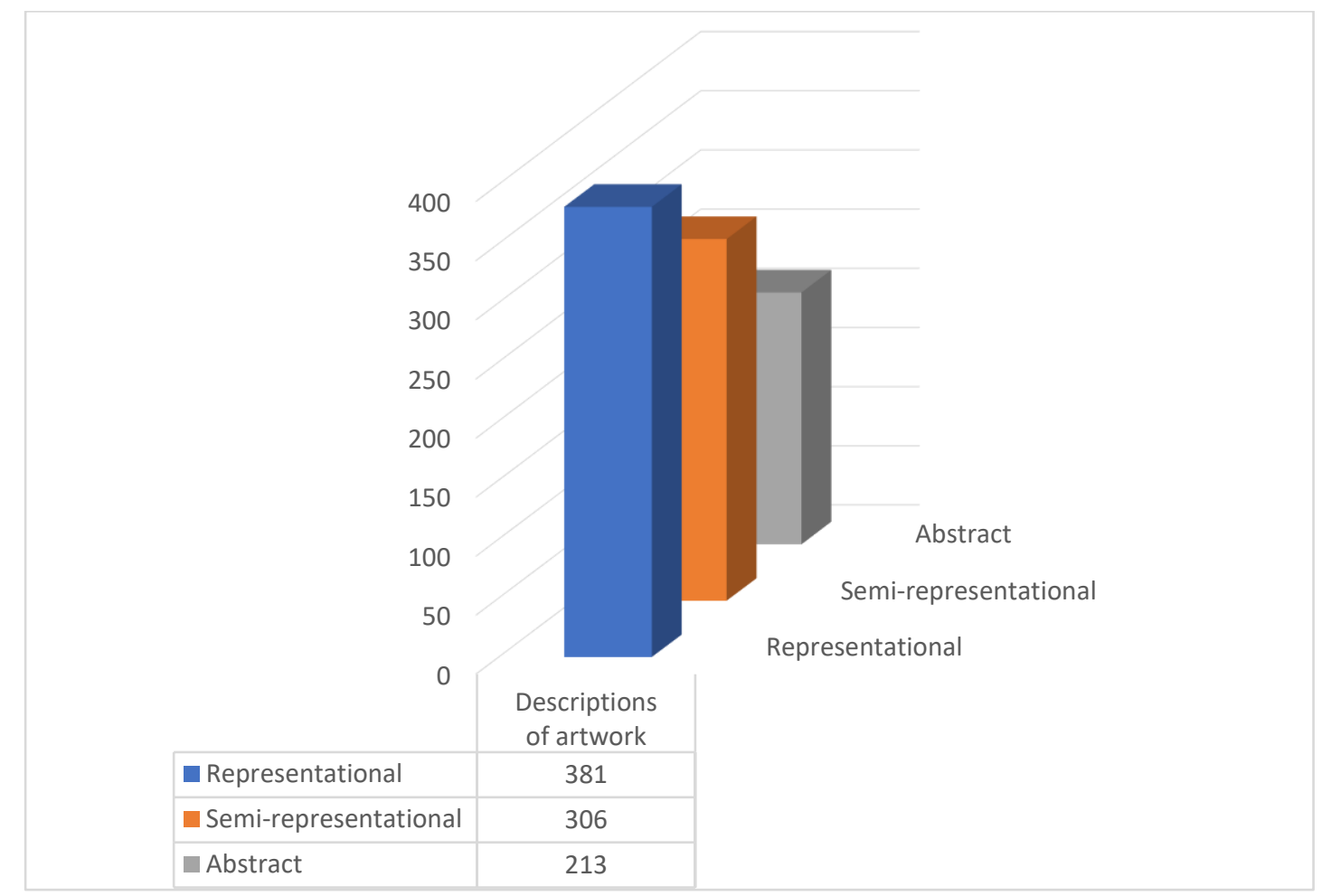

Figure 2: Overall appreciation of artworks by genre 
The analysis of the overall appreciation of three genres of artworks shows that the total scores for appreciation of representational, semi-representational and abstract artworks are 381, 306 and 213, respectively. To conclude, the scores of appreciation of representational artworks is higher than the other two genres of artworks.

As discussed above, a difference is noted between the appreciation of representational, semi-representational and abstract artworks by children. It is therefore required to assess if the differences of appreciation in the three genres of artworks is statistically significant or not. Hence, the following hypothesis is formulated:

$\mathbf{H}_{1}$ : There is a significant difference between children's appreciation of representational, semi-representational and abstract artworks.

To test this hypothesis, the above hypothesis is translated into null form.

$\mathbf{H}_{0}$ : There is no significant difference between children's appreciation of representational, semi-representational and abstract artworks.

Friedman test is used to test the above null hypothesis and the results are presented below:

Table 2: Friedman test results - Overall appreciation of artworks by genre

\begin{tabular}{|l|c|c|c|c|}
\hline \multirow{2}{*}{} & \multirow{2}{*}{$\mathbf{N}$} & \multicolumn{3}{|c|}{ Percentiles } \\
\cline { 3 - 5 } & & 25th & 50th (Median) & 75th \\
\hline Representational & 60 & 6.0000 & 6.0000 & 7.0000 \\
\hline Semi-representational & 60 & 4.0000 & 5.0000 & 6.0000 \\
\hline Abstract & 60 & 3.0000 & 3.0000 & 4.0000 \\
\hline
\end{tabular}

Table 3: Test statistics - Friedman test

\begin{tabular}{|l|c|}
\hline $\mathrm{N}$ & 60 \\
\hline Chi-Square & 104.183 \\
\hline $\mathrm{df}$ & 2 \\
\hline Asymp. Sig. & .000 \\
\hline
\end{tabular}

From the above results, it is observed the $\chi^{2}$ value at 2 degrees of freedom and at the significance level 0.000 is 104.183. ' $p$ ' value is a probability that measures evidence against the null hypothesis. If $\mathrm{p}$ values are small, it indicates rejection of null hypothesis. $\mathrm{p}$ value is 0.000 , and the null hypothesis stands rejected. Therefore, it is inferred that there exists a statistically significant difference in the appreciation of artworks depending on the genre of artworks, $\chi^{2}(2)=104.183$, $p=0.000$.

To examine where the differences occur, a separate Wilcoxon signed ranks test is conducted on different combinations of the three genres of artworks.

Table 4: Test statistics - Wilcoxon signed ranks test

\begin{tabular}{|l|c|c|c|}
\hline & $\begin{array}{c}\text { Semi-representational - } \\
\text { Representational }\end{array}$ & $\begin{array}{c}\text { Abstract - } \\
\text { Representational }\end{array}$ & $\begin{array}{c}\text { Abstract - } \\
\text { Semi-representational }\end{array}$ \\
\hline Z & $-6.774^{\mathrm{b}}$ & $-6.627^{\mathrm{b}}$ & $-6.055^{\mathrm{b}}$ \\
\hline Asymp. Sig. (2-tailed) & .000 & .000 & .000 \\
\hline \multicolumn{2}{l|}{ b. Based on positive ranks }
\end{tabular}


The above table provides the results of post-hoc analysis using Wilcoxon signed ranks test (with a Bonferroni correction applied, significance level is set at $\mathrm{p}<0.017$ ) on each of the combinations. Median (Inter Quartile Range) descriptions of artworks of representational, semirepresentational and abstract artworks are 6.0 (6 to 7), 5.0 (4 to 6) and 3.0 (3 to 4) respectively. The results show that there are statistically significant differences between children's appreciation of representational and semi-representational artworks $(Z=-6.774, p=0.000)$, representational and abstract artworks $(Z=-6.627, p=0.000)$ and semi-representational and abstract artworks $(Z=-6.055, \mathrm{p}=0.000)$.

\subsection{Children's appreciation of artworks with respect to type of paintings}

Children's appreciation of representational, semi-representational and abstract artworks is analysed quantitatively with respect to type of paintings. Children are shown three types of paintings namely western, middle eastern and oriental paintings. Art appreciation is obtained from the description of artworks by children. Children's descriptions are scored on a continuous scale of 1-10 for representational, semi-representational and abstract artworks. The scores are tabulated for the three genres of artworks. The results of analysis of appreciation of artworks with respect to type of paintings are presented below.

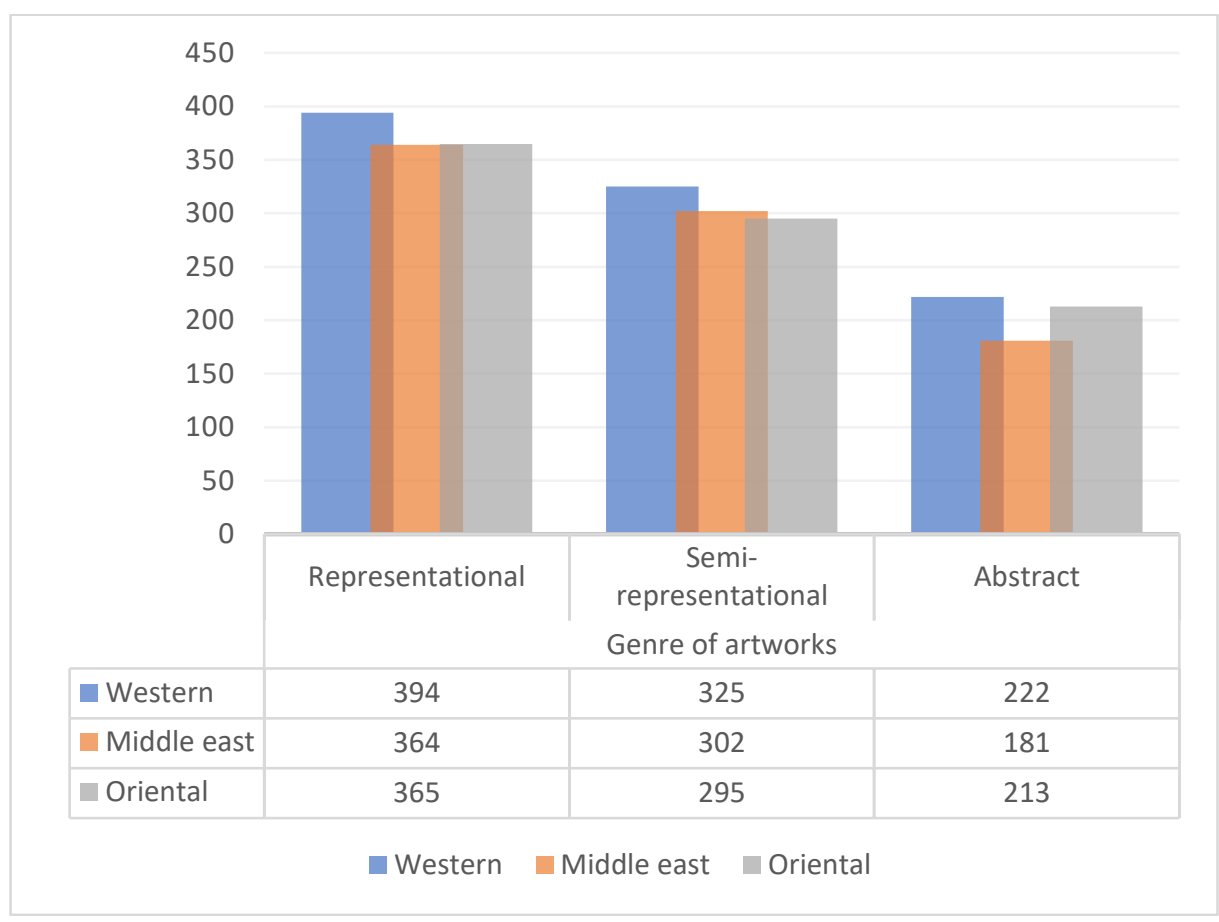

Figure 3: Appreciation of artworks with respect to type of paintings

The analysis of appreciation of three genres of artworks with respect to three types of paintings are given below. Children's total scores for representational artworks of western, middle eastern and oriental type of paintings are 394, 364 and 365, respectively. Children's total scores for semi-representational artworks of western, middle eastern and oriental type of paintings are 325, 302 and 295, respectively. Children's total scores for abstract artworks of western, middle eastern and oriental type of paintings are 222, 181 and 213 respectively. 
The results show differences in the appreciation of artworks with respect to type of paintings.

\subsection{Appreciation of representational artworks by type of paintings}

As shown in Figure 3 above, a difference is noted between the appreciation of western, middle eastern and oriental type of paintings with respect to the genre of representational artworks. It is therefore required to assess if the differences between the appreciation of representational artworks of the three types of paintings is statistically significant or not. Hence, the following hypothesis is formulated:

$\mathbf{H}_{1}$ : There is a significant difference in the appreciation of representational artworks depending on the type of paintings.

To test this hypothesis, the above hypothesis is translated into null form.

$\mathbf{H}_{0}$ : There is no significant difference in the appreciation of representational artworks depending on the type of paintings.

Friedman test is employed to test the null hypothesis and the results are shown below:

Table 5: Friedman test results - Appreciation of representational artworks by type of paintings

\begin{tabular}{|l|c|c|c|c|}
\hline \multirow{2}{*}{ Representational artworks } & \multirow{2}{*}{$\mathbf{N}$} & \multicolumn{3}{|c|}{ Percentiles } \\
\cline { 3 - 5 } & & 25th & 50th (Median) & 75th \\
\hline Western & 60 & 6.0000 & 6.0000 & 7.0000 \\
\hline Middle Eastern & 60 & 5.0000 & 6.0000 & 7.0000 \\
\hline Oriental & 60 & 5.0000 & 6.0000 & 6.7500 \\
\hline
\end{tabular}

Table 6: Test statistics - Friedman test

\begin{tabular}{|l|c|}
\hline $\mathrm{N}$ & 60 \\
\hline Chi-Square & 17.077 \\
\hline $\mathrm{df}$ & 2 \\
\hline Asymp. Sig. & .000 \\
\hline
\end{tabular}

From the results presented above, it is observed that the $\chi^{2}$ value at 2 degrees of freedom is 17.077 and the significance level is 0.000. $\mathrm{p}$ value is a probability that measures evidence against the null hypothesis. $p$ value is 0.000 and the null hypothesis stands rejected. Therefore, it is inferred that there is a statistically significant difference in appreciation of representational artworks depending on the type of paintings, $\chi^{2}(2)=17.077, p=0.000$.

To examine where the differences occur, a separate Wilcoxon signed ranks test is conducted on different combinations of the three types of paintings.

Table 7: Test statistics - Wilcoxon signed ranks test

\begin{tabular}{|l|c|c|c|}
\hline Representational artworks & Western-Middle Eastern & Western-Oriental & Middle Eastern-Oriental \\
\hline$Z$ & $-3.307^{\mathrm{b}}$ & $-3.384^{\mathrm{b}}$ & $-0.164^{\mathrm{b}}$ \\
\hline Asymp. Sig. (2-tailed) & .001 & .001 & .870 \\
\hline b. Based on positive ranks & \multicolumn{3}{|l}{} \\
\hline
\end{tabular}

The above table provides the results of post-hoc analysis using Wilcoxon signed ranks test (with a Bonferroni correction applied, significance level is set at $\mathrm{p}<0.017$ ) on each of the combinations. 
Median (Inter Quartile Range) descriptions of artworks of western, middle eastern and oriental paintings are 6.0 (6 to 7), 6.0 (5 to 7) and 6.0 (5 to 6.75) respectively. The results show that there are statistically significant differences between the appreciation of western and middle eastern paintings $(Z=-3.307, p=0.001)$, western and oriental paintings $(Z=-3.384, p=0.001)$ and there exists no statistically significant differences between the appreciation of oriental and middle eastern paintings $(Z=-0.164, p=0.870)$.

\subsection{Appreciation of semi-representational artworks by type of paintings}

In Figure 3 shown above, a difference is noted between the appreciation of western, middle eastern and oriental paintings with respect to the genre of semi-representational artworks. It is therefore required to assess if the differences in the appreciation of semi-representational artworks by the three types of paintings is statistically significant or not. Hence, the following hypothesis is formulated:

$\mathbf{H}_{1}$ : There is a significant difference in the appreciation of semi-representational artworks depending on the type of paintings.

To test this hypothesis, the above hypothesis is translated into null form.

$\mathbf{H}_{0}$ : There is no significant difference in the appreciation of semi-representational artworks depending on the type of paintings.

Friedman test is used to test the above null hypothesis and the results are presented below:

Table 8: Friedman test results - Appreciation of semi-representational artworks by type of paintings

\begin{tabular}{|l|c|c|c|c|}
\hline \multirow{2}{*}{ Semi-representational artworks } & \multirow{2}{*}{$\mathbf{N}$} & \multicolumn{3}{|c|}{ Percentiles } \\
\cline { 3 - 5 } & & 25th & 50th (Median) & 75th \\
\hline Western & 60 & 4.2500 & 5.0000 & 6.0000 \\
\hline Middle Eastern & 60 & 4.0000 & 5.0000 & 6.0000 \\
\hline Oriental & 60 & 4.0000 & 5.0000 & 6.0000 \\
\hline
\end{tabular}

Table 9: Test statistics - Friedman test

\begin{tabular}{|l|c|}
\hline $\mathrm{N}$ & 60 \\
\hline Chi-Square & 12.340 \\
\hline $\mathrm{df}$ & 2 \\
\hline Asymp. Sig. & .002 \\
\hline
\end{tabular}

The table presented above shows that the $\chi^{2}$ value at 2 degrees of freedom is 12.340 and the significance level is 0.002 . Since $p$ value is 0.002 , the null hypothesis stands rejected. Therefore, it is inferred that there is a statistically significant difference in the appreciation of semirepresentational artworks depending on the type of paintings, $\chi^{2}(2)=12.340, p=0.002$.

To examine where the differences occur, a separate Wilcoxon signed ranks test is conducted on different combinations of the three types of paintings.

Table 10: Test Statistics - Wilcoxon signed ranks test

\begin{tabular}{|l|c|c|c|}
\hline Semi-representational artworks & Western-Middle Eastern & Western-Oriental & Middle Eastern-Oriental \\
\hline$Z$ & $-2.463^{\mathrm{b}}$ & $-3.198^{\mathrm{b}}$ & $-1.084^{\mathrm{b}}$ \\
\hline Asymp. Sig. (2-tailed) & .014 & .001 & .279 \\
\hline b. Based on positive ranks & & \\
\hline
\end{tabular}


The above table provides the results of post-hoc analysis using Wilcoxon signed ranks test (with a Bonferroni correction applied, significance level is set at $\mathrm{p}<0.017$ ) on each of the combinations. Median (Inter Quartile Range) descriptions of artworks of western, middle eastern and oriental paintings are 5.0 (4.25 to 6), 5.0 (4 to 6 ) and 5.0 (4 to 6) respectively. The results show that there are statistically significant differences between the appreciation of western and middle eastern paintings $(Z=-2.463, p=0.014)$, western and oriental paintings $(Z=-3.198, p=0.001)$ and there exists no statistically significant differences between the appreciation of oriental and middle eastern paintings $(Z=-1.084, p=0.279)$.

\subsection{Appreciation of abstract artworks by type of paintings}

The Figure 3 presented above shows a difference in the appreciation of western, middle eastern and oriental paintings with respect to the genre of abstract artworks. It is therefore required to assess if the differences between the appreciation of abstract artworks of the three types of paintings is statistically significant or not. Hence, the following hypothesis is formulated:

$\mathbf{H}_{1}$ : There is a significant difference in the appreciation of abstract artworks depending on the type of paintings.

To test this hypothesis, the above hypothesis is translated into null form.

$\mathbf{H}_{0}$ : There is no significant difference in the appreciation of abstract artworks depending on the type of paintings.

Friedman test is used to test the null hypothesis and the results are presented below:

Table 11: Friedman test results - Appreciation of abstract artworks by type of paintings

\begin{tabular}{|l|c|c|c|c|}
\hline \multirow{2}{*}{ Abstract artworks } & \multirow{2}{*}{$\mathbf{N}$} & \multicolumn{3}{|c|}{ Percentiles } \\
\cline { 3 - 5 } & & 25th & 50th (Median) & 75th \\
\hline Western & 60 & 3.0000 & 3.0000 & 4.0000 \\
\hline Middle Eastern & 60 & 2.0000 & 3.0000 & 3.0000 \\
\hline Oriental & 60 & 2.0000 & 3.0000 & 4.0000 \\
\hline
\end{tabular}

Table 12: Test statistics - Friedman test

\begin{tabular}{|l|c|}
\hline $\mathrm{N}$ & 60 \\
\hline Chi-Square & 23.738 \\
\hline $\mathrm{df}$ & 2 \\
\hline Asymp. Sig. & .000 \\
\hline
\end{tabular}

The above results show that the $\chi^{2}$ value at 2 degrees of freedom is 23.738 and the significance level is 0.000 . Since $p$ value is 0.000 , the null hypothesis stands rejected. Therefore, it is inferred that there is a statistically significant difference in the appreciation of abstract artworks depending on the type of paintings, $\chi^{2}(2)=23.738, p=0.000$.

To examine where the differences occur, a separate Wilcoxon signed ranks test is conducted on different combinations of the three types of paintings. 
Table 13: Test Statistics - Wilcoxon signed ranks test

\begin{tabular}{|l|c|c|c|}
\hline Abstract artworks & Western-Middle Eastern & Western-Oriental & Middle Eastern-Oriental \\
\hline$Z$ & $-4.787^{\mathrm{b}}$ & $-1.023^{\mathrm{b}}$ & $-3.040^{\mathrm{b}}$ \\
\hline Asymp. Sig. (2-tailed) & .000 & .306 & .002 \\
\hline b. Based on positive ranks
\end{tabular}

The above table provides the results of post-hoc analysis using Wilcoxon signed ranks test (with a Bonferroni correction applied, significance level is set at $\mathrm{p}<0.017$ ) on each of the combinations. Median (Inter Quartile Range) descriptions of artworks of western, middle eastern and oriental paintings are 3.0 (3 to 4), 3.0 (2 to 3 ) and 3.0 (2 to 4 ) respectively. The results show that there are statistically significant differences between the appreciation of western and middle eastern paintings $(Z=-4.787, p=0.000)$, middle eastern and oriental paintings $(Z=-3.040, p=0.002)$ and there exists no statistically significant differences between the appreciation of oriental and western paintings $(Z=-1.023, p=0.306)$.

Children's scores for appreciation of artworks indicate that children appreciated representational artworks more than semi-representational artworks and their appreciation of abstract artworks is minimum. This is attributed to the finding that classical art has clear content, and it is comprehended better by viewers (Leder et al., 2012). The statistical analysis of overall appreciation of three genres of artworks reveal that there exists a statistically significant difference in the appreciation of artworks depending on the genre of artworks. Children's appreciation of artworks according to the type of paintings indicate differences in appreciation among western, middle eastern and oriental paintings. Scores of appreciations indicate higher scores for western paintings under all three genres of artworks. Statistical analysis demonstrates that there exist statistically significant differences in the appreciation of representational, semirepresentational and abstract artworks depending on the type of paintings.

The results presented above are in conformity with earlier studies which shows that children described more about Representational artworks and least about Abstract artworks. Thus, the results support the past findings that children's appreciation of artworks varies based on the genre of painting. The more realistic the artwork, the more children focus on what they see in the artwork and understand the artwork. Children find it difficult to understand and explain abstract artworks. This confirms the findings by Leder \& Nadal (2014) that aesthetic appreciation of artworks depends strongly on aspects of cognitive mastering. This results also corroborates Leder et. al.'s (2004) hypothesis that comprehension of an artwork is based on content representation in the artwork and Representative classical artworks were understood better by viewers (Leder et al., 2012). The results also show children's capability to apply prior knowledge to novel situations to interpret artworks. It was evident in their references made to Biblical stories while describing the artworks.

\section{Conclusion}

The present study explored how children appreciate art by viewing artworks of different genres and types. The results of this study showed that children can respond to artworks visually, cognitively, and semantically. Children described, explained, and elaborated on their observations. Art appreciation enhances children's ability to make opinions and articulate their 
thoughts and feelings. The findings of this study can be used to enlighten the development of art education curricula. Perceiving artworks needed some skills for comprehending and interpreting the content. Teaching children the needed skills for viewing artworks will help them understand themselves, others, history, and culture. Educational institutions should employ creative ways of providing the benefits of art to children. For this, involving children in art viewing and art appreciation would be an ideal choice. With increasing technology teachers may use digitized collections of artworks in order to provide access to art and to augment student engagement with art. This will help towards democratizing art.

\section{About the Author(s)}

Lilly K. V. is currently undertaking her PhD in Education at The English and Foreign Languages University, Hyderabad, India. She holds master's degrees in Chemistry and Education. Her areas of research interests are Art Studies, Science Education, Pedagogical Sciences, and Cognitive Science.

Sudhakar Venukapalli is currently working as the Professor of Education at The English and Foreign Languages University, Hyderabad, India. His research areas of interest are Cognitive Science, Philosophy of Science, Policy Studies in Education and Liberal Arts Education.

\section{References}

Anderson, D., Piscitelli, B., Weir, K., Everett, M. \& Tayler, C. (2002). Children's museum experiences: Identifying powerful mediators of learning. Curator, 45, 213-231. Retrieved from http://www.magsq.com.au/ dbase upl/curator andersonetal\%20copy.pdf.

Ariffin, M. S. N. (2010). Sejauhmana keberkesanan perlaksanaan sesi apresiasi seni di sekolah menengah dalam pendidikan seni. In Ping, C. T. S., \& Ladin, C. A. (2019). Applications of Art Appreciation in Teaching and Learning in Primary School. International Journal of Academic Research in Progressive Education and Development, 8(4): 130-140. doi: 10.6007/IJARPED/v8-i4/6441.

Armstrong, T., \& Detweiler-Bedell, B. (2008). Beauty as an emotion: the exhilarating prospect of mastering a challenging world. Review of General Psychology, 12, 305- 329. doi:10.1037/a0012558.

Bao, Y., Yang T, Lin X, Fang Y, Wang Y, Pöppel E \& Lei, Q. (2016). Aesthetic preferences for eastern and western traditional visual art: Identity matters. Frontiers in Psychology, 7(2143). doi: 10.3389/fpsyg.2016.01596.

Barron, F. \& Welsh, G. S. (1952). Artistic perception as a possible factor in personality style: Its measurement by a figure preference test. The Journal of Psychology: Interdisciplinary and Applied, 33, 199-203. doi: https://doi.org/10.1080/00223980.1952.9712830.

Bellanca, J. A., \& Brandt, R. S. (2010). 21 ${ }^{\text {st }}$ Century skills: Rethinking how students learn. Solution Tree Press. Retrieved from http://soltreemrls3.s3-website-us-west2.amazonaws.com/solutiontree.com/media/pdf/study guides/21st Century Skills Study Guide.pdf. 
Brinkmann, H., Commare, L., Leder, H., \& Rosenberg, R. (2014). Abstract art as a universal language? Leonardo, 47(3): 256-257.doi: 10.1162/LEON_a_00767.

Burchenal, P., Housen, A., Rawlinson, K., \& Yenawine, P. (2008). Why Do we teach Arts in the Schools? Advancing Art Education, 50(2). A Publication of the National Art Education Association. Retrieved from https://vtshome.org/wp-content/uploads/2016/08/17whydo-we-teach-art-in-the-schools NAEANews April08.pdf.

Chatterjee, A. (2003). Prospects for a cognitive neuroscience of a visual aesthetics. Bulletin of Psychology and the Arts, 4, 55-60. doi: 10.1037/e514602010-003.

Eckhoff, A. (2010). Using games to explore visual art with young children. Young Children, 65(1): 18-22. Retrieved from https://www.researchgate.net/publication/290551309.

Efland, A. D. (2002). Art and cognition: Integrating the visual arts in the curriculum. New York, NY: Teachers College Press.

Eglinton, K. A. (2003). Art in the early years. London: Routledge Falmer. Retrieved from https://books.google.co.in/books/about/Art in the Early Years.html?id=r1dORy41UWc C\&redir esc $=y$.

Gardner, H., Winner, E., \& Kirchner, M. (1975). Children's conceptions of the Arts. Journal of Aesthetic Education, 9 (3), 60-77. Retrieved from http://links.jstor.org/sici?sici=00218510\%28197507\%299\%3A3\%3C60\%3ACCOTA\%3E2.0.CO\%3B2-F.

House, C. A. \& Rule, A. C. (2005). Pre-schoolers' ideas of what makes a picture book illustration beautiful. Early Childhood Education Journal, 32(5): 283-290. doi:10.1007/s10643-004-1022-7.

Housen, A. (2002). Aesthetic thought, critical thinking and transfer. Art and Learning Research Journal, 18, 99-132. Retrieved from https://pdfs.semanticscholar.org/f92a/f0a61718efaca853d456c1edec6817dfee31.pdf? ga=2 $.174320491 .838978140 .1577727629-127502483.1577727629$.

Jiao, L. (2019). Analysis of Relationship between Arts Education and Spread of Modern Culture. Journal of Social Science Studies, Volume 3. doi: 10.35532/JSSS.V3.189. Google scholar

Kieran, M. (2012). For love of art: artistic values and appreciative virtues. In Sherman, A. \& Morrissey, C. (2017). What Is Art Good For? The Socio-Epistemic Value of Art. Frontiers in Human Neuroscience, 11:411. doi: 10.3389/fnhum.2017.00411.

Kolbe, U. (2002). Rapunzel's supermarket: All about young children and their art. Paddington, NSW: Peppinot Press. Retrieved from https://books.google.co.in/books/about/Rapunzel s Supermarket.html?id=zMqiAAAA CAAI\&redir esc $=y$.

Law, S. S. M. (2010). An Interdisciplinary Approach to Art Appreciation. New Horizons in Education, 58(2). Retrieved from https:/files.eric.ed.gov/fulltext/EJ966652.pdf.

Leder, H. \& Nadal, M. (2014). Ten years of a model of aesthetic appreciation and aesthetic judgments: The aesthetic episode - Developments and challenges in empirical aesthetics. British Journal of Psychology, 105(4), 443-464. doi: 10.1111/bjop.12084.

Leder, H., Belke, B., Oeberst, A., \& Augustin, D. (2004). A model of aesthetic appreciation and aesthetic judgments. British Journal of Psychology, 95, 489-508. doi:10.1348/0007126042369811. 
Leder, H., Carbon, C. C., \& Ripsas, A. L. (2006). Entitling art: influence of title information on understanding and appreciation of paintings. Acta Psychologica, 121, 176-198. doi: 10.1016/j.actpsy.2005.08.005.

Leder, H., Gerger, G., Dressler, S., \& Schabmann, A. (2012). How art is appreciated. Psychology of Aesthetics, Creativity, and the Arts, 6(1): 2-10. doi:10.1037/a0026396.

Maneen, C. A. (2016). A case study of arts integration practices in developing the 21st century skills of critical thinking, creativity, communication, and collaboration. Gardner-Webb University, Retrieved from https://digitalcommons.gardner-webb.edu/education etd/182

McArdle, F. \& Wright, S. (2014). First literacies: art, creativity, play, constructive meaning making. In G. Barton (Ed.), Literacy in the Arts: Retheorising learning and teaching. In Lye, J. W. Y., Garces-Bacsal, R. M., \& Wright, S. K. (2017). Young children's responses to artworks: The eye, the mind, and the body. International Journal of Education $\mathcal{E}$ the Arts, 18(30). Retrieved from http://www.ijea.org/v18n30/.

Mulcahey, C. (2009). Providing rich art activities for young children. Young Children, 64(4), 107112. Retrieved from https://eric.ed.gov/?id=EJ868189.

Munsinger, H., Kessen, W., \& Kessen, M.L. (1964). Age and uncertainty: Developmental variation in preference for variability. Journal of Experimental Child Psychology, 1(1):1-15. doi: https://doi.org/10.1016/0022-0965(64)90002-5.

Novaković, S. (2015). Preschool teacher's role in the art activities of early and preschool age children. Croatian Journal of Education, 17(0). doi:10.15516/cje.v17i0.1497.

Palmer, S. E., Schloss, K. B., \& Sammartino, J. (2013). Visual aesthetics and human preference. Annual Review of Psychology, 64, 77-107. doi: 10.1146/annurevpsych-120710-100504.

Perkins, D. (2003). Making thinking visible. Harvard Project Zero. Retrieved from http://www.pz.harvard.edu/sites/default/files/MakingThinkingVisible DP.pdf.

Reber, R., Schwarz, N., \& Winkielman, P. (2004). Processing fluency and aesthetic pleasure: Is beauty in the perceiver's processing experience? Personality and Social Psychology Review, 8(4):364-82. doi:10.1207/s15327957pspr0804_3.

Reber, R., Winkielman, P., \& Schwarz, N. (1998). Effects of perceptual fluency on affective judgments. Psychological Science, 9, 45-48. doi: 10.1111/1467-9280. 00008.

Rudolf, S. \& Wright, S. (2015). Drawing out the value of the visual: children and young people theorizing time through art and narrative. Journal of Curriculum Studies, 47(4), 486-507. Retrieved from https://doi.org/10.1080/00220272.2015.1006685.

Savva, A. (2003). Young Pupil's Responses to Adult Works of Art. Contemporary Issues in Early Childhood, 4(3). doi: 10.2304/ciec.2003.4.3.6.

Savva, A. \& Trimis, E. (2005). Responses of young children to contemporary art exhibits: The role of artistic experiences. International Journal of Education and the Arts, 6(13). Retrieved from http://ijea.asu.edu/v6n13/

Schabmann, A., Gerger, G., Schmidt, B. M., \& Wogerer, E. (2015). Where does it come from? Developmental aspects of art appreciation. International Journal of Behavioural Development, 1-11, ijbd.sagepub.com. doi:10.1177/0165025415573642.

Terreni, L. (2016). Visual arts education for young children in Aotearoa New Zealand. Journal of Childhood Studies, 41(4). doi:10.18357/jcs. v41i4.16718. 
Winkielman, P., Halberstadt, J., Fazendeiro, T., \& Catty, S. (2006). Prototypes are attractive because they are easy on the mind. Psychological Science, 17(9):799-806. doi:10.1111/j.14679280.2006. 01785.x.

Winston, A. S. \& Cupchik, G. C. (1992). The evaluation of high art and popular art by naive and experienced viewers. Visual Arts Research, 18(1), 1-14. Retrieved from http://www.jstor.org/stable/20715763. 
Appendix: List of paintings

1. Pastoral Landscape, Asher Brown Durand,1861, Hudson River School.

2. Water lilies, Claude Monet, 1917, Impressionism.

3. Landscapes with Red spots no. 2, Wassily Kandinsky, 1913, Abstraction.

4. An Arab encampment at Sunset, Herman David Salomon Corrodi.

5. Middle eastern city, unknown, Early $20^{\text {th }}$ century.

6. Abstract landscape, Shafic Abboud, 1959.

7. The Watercolour Log, Milind Mulick, contemporary.

8. Dancing and Singing (Peasants Returning from Work), Ma Yuan, $13^{\text {th }}$ century.

9. The First Light, Chu Teh Chun, 1987. 
Creative Commons licensing terms

Author(s) will retain the copyright of their published articles agreeing that a Creative Commons Attribution 4.0 International License (CC BY 4.0) terms will be applied to their work. Under the terms of this license, no permission is required from the author(s) or publisher for members of the community to copy, distribute, transmit or adapt the article content, providing a proper, prominent and unambiguous attribution to the authors in a manner that makes clear that the materials are being reused under permission of a Creative Commons License. Views, opinions and conclusions expressed in this research article are views, opinions and conclusions of the author(s). and European Journal of Literature, Language and Linguistics Studies shall not be responsible or answerable for any loss, damage or liability caused in relation to/arising out of conflicts of interest, copyright violations and inappropriate or inaccurate use of any kind content related or integrated into the research work. All the published works are meeting the Open Access Publishing requirements and can be freely accessed, shared, modified, distributed and used in educational, commercial and non-commercial purposes under a Creative Commons Attribution 4.0 International License (CC BY 4.0). 